\title{
Genetic Diversity and Population Structure Analysis of Wild Cymbidium tortisepalum Based on Chloroplast DNA in Yunnan Province of China
}

\author{
Xiangli Ma \\ College of Animal Science and Technology, Yunnan Agricultural University, Kunming 650201, \\ China \\ Min Tang \\ College of Horticulture and Landscape, Yunnan Agricultural University, Kunming 650201, China \\ Yufen Bi \\ College of Animal Science and Technology, Yunnan Agricultural University, Kunming 650201, \\ China

\begin{abstract}
Junbo Yang
Germplasm Bank of Wild Species in Southwest China, Kunming Institute of Botany, Chinese Academy of Sciences, Kunming 650204, China
\end{abstract}

\begin{abstract}
Additional INDEX WORDs. conservation, genetic differentiation, orchid, three parallel rivers region
Abstract. Cymbidium tortisepalum is a primary orchid species in Yunnan Province, China, and has an extremely high ornamental and economic value. To reveal the levels and distribution of genetic variation and structure of wild $C$. tortisepalum resources, sequence variations of six chloroplast DNA intergenic spacers (psbM-trnD, $\operatorname{trnV} V-\operatorname{trn} A$, accD-psal, rrn23, trnk-rps16, and ycf1) were analyzed in 404 wild individuals from 28 populations in the three river area in Yunnan Province, China. The results showed that the six chloroplast DNA sequences were aligned with 61 polymorphic sites, including 50 indels and 11 haplotypes in 404 individuals, which revealed a low level of genetic diversity (total genetic diversity $=\mathbf{0 . 2 4 0}$, and the average value of nucleotide diversity $=0.00024$ ). In addition, a fairly low genetic differentiation [coefficients for genetic differentiation among populations $\left(G_{S T}\right)=0.099$, number of substitution $\left(N_{S T}\right)=0.081$ ] was found among the studied populations, and $N_{S T}$ value was less than $G_{S T}$, which indicated that no significant phylogeographic structure existed in those populations. Furthermore, analysis of molecular variance revealed that great genetic variance $(91 \%)$ came from individuals within the populations, which indicated that there was no clear genetic differentiation among populations. On the basis of these findings, a conservation plan was proposed to sample or preserve fewer populations but with more individuals from each population.
\end{abstract}

Cymbidium tortisepalum is a perennial herb, which belongs to Orchidaceae family (Du Puy and Cribb, 1988). Wild C. tortisepalum mainly grows in the river valleys or under secondary forest of Pinus yunnanensis, Abies fabri, and Quercus aquifolioides in the middle of the mountains, with a range of 1000 to $2700 \mathrm{~m}, 70 \%$ to $80 \%$ shading intensities, and $60 \%$ to $80 \%$ air humidity, and where the soil is moist all year with a high nutrient content and $\mathrm{pH}$ between 5.5 and 6.5 (Xue et al., 2007). Because this plant has an extremely narrow geographic spread, high dependence on ecological environment, and poor natural reproduction ability, its wild resources are rare, being scattered only within Taiwan Province, the southwest of Sichuan Province, and the northwest of Yunnan Province, China (Lin et al., 2016;

Received for publication 20 Jan. 2021. Accepted for publication 11 Aug. 2021.

Published online 30 September 2021

This study was supported by the National Science Foundation of China Genetic Response Mechanism of Main Ecological Factors for Populations of Wild Cymbidium Tortisepalum in Yunnan Province (no. 31260487) and the Germplasm Bank of Wild Species in Southwest China.

X.M. and M.T. contributed equally to this work.

Y.B. is the corresponding author. E-mail: biyufenynnd@sina.com.

This is an open access article distributed under the CC BY-NC-ND license (https://creativecommons.org/licenses/by-nc-nd/4.0/).
Peng, 2003). It is primarily distributed in the three parallel river region (Jinsha, Lancang, and Nujiang rivers) of the northwestern Yunnan Province, at latitude $24^{\circ} \mathrm{N}$ to $28.4^{\circ} \mathrm{N}$ and longitude $98^{\circ} \mathrm{E}$ to $101^{\circ} \mathrm{E}$. C. tortisepalum is famous for its graceful shape, varied flowers, and beautiful color, which gives it a high ornamental and economic value, and it has become one of the most sought-after orchid species in Yunnan Province (Du Puy and Cribb, 1988). The $C$. tortisepalum industry has reached a value of more than 100 million yuan in the Yunnan (Qi, 2004). With increased market, the price of one wild $C$. tortisepalum can reach up to tens of thousands and even millions of yuan. Consequently, the wild resources of $C$. tortisepalum in Yunnan Province are being diminished by overexploitation and habitat loss (Rao et al., 2008; Xue et al., 2007). Therefore, the research on germplasm resources, and the evaluation of the genetic diversity and structure of wild $C$. tortisepalum in Yunnan Province, could provide valuable knowledge to the protection of wild resources. However, current studies of $C$. tortisepalum, both within China and abroad, are mainly focused on cultivation management (He et al., 2019), tissue culture, and rapid propagation (Huan et and Tanake, 2004; Teixeira da Silva et al., 2006), and cross-breeding (Li et al., 2009, 2010; Zhao et al., 2019). Reports of genetic diversity and genetic structure of wild $C$. tortisepalum are 
Table 1. Details of sampling sites of 28 populations of wild Cymbidium tortisepalum in Yunnan Province, China. From 2010 to 2011 , we collected 404 individuals from 28 naturally distributed populations of C. tortisepalum in northwestern Yunnan. Approximately 15 to 24 individuals were selected from each population with a distance at least $20 \mathrm{~m}$.

\begin{tabular}{|c|c|c|c|c|c|c|c|}
\hline Region $^{\mathrm{z}}$ & Population & Location name & $\mathrm{N}$ & Habitat $^{\mathrm{y}}$ & Latitude $(\mathrm{N})$ & Longitude (E) & Altitude (m) \\
\hline \multirow[t]{6}{*}{ NW } & $\mathrm{BD}$ & $\begin{array}{l}\text { Badi Township, Weixi County, } \\
\text { Diqing Tibetan Autonomous } \\
\text { Prefecture }\end{array}$ & 15 & $\begin{array}{l}\text { Pine forest, mountain } \\
\text { slope }\end{array}$ & $27^{\circ} 54^{\prime} 04.37^{\prime \prime}$ & $98^{\circ} 56^{\prime} 46.47^{\prime \prime}$ & 1908 \\
\hline & WD & $\begin{array}{l}\text { Weideng Township, Weixi } \\
\text { County, Diqing Tibetan } \\
\text { Autonomous Prefecture }\end{array}$ & 17 & $\begin{array}{l}\text { Pine and oak mixed } \\
\text { forest, vale }\end{array}$ & $27^{\circ} 04^{\prime} 08.04^{\prime \prime}$ & $99^{\circ} 10^{\prime} 49.88^{\prime \prime}$ & 1945 \\
\hline & ZL & $\begin{array}{c}\text { Zhonglu Township, Weixi } \\
\text { County, Diqing Tibetan } \\
\text { Autonomous Prefecture }\end{array}$ & 18 & $\begin{array}{l}\text { Pine and oak mixed } \\
\text { forest, mountain } \\
\text { slope }\end{array}$ & $27^{\circ} 09^{\prime} 28.58^{\prime \prime}$ & $99^{\circ} 09^{\prime} 32.00^{\prime \prime}$ & 1715 \\
\hline & $\mathrm{CK}$ & $\begin{array}{l}\text { Cikai Township, Gongshan } \\
\text { County, Nujiang Lisu } \\
\text { Autonomous Prefecture }\end{array}$ & 15 & $\begin{array}{l}\text { Bamboo grove, } \\
\text { escarpment }\end{array}$ & $27^{\circ} 41^{\prime} 46.61^{\prime \prime}$ & $98^{\circ} 41^{\prime} 57.31^{\prime \prime}$ & 1609 \\
\hline & $\mathrm{ZP}$ & $\begin{array}{c}\text { Zhongpai Township, Lanping } \\
\text { County, Nujiang Lisu } \\
\text { Autonomous Prefecture }\end{array}$ & 14 & $\begin{array}{l}\text { Pine and oak mixed } \\
\text { forest, valley }\end{array}$ & $26^{\circ} 55^{\prime} 37.15^{\prime \prime}$ & $99^{\circ} 11^{\prime} 12.06^{\prime \prime}$ & 1719 \\
\hline & HS & $\begin{array}{l}\text { Huangshan Township, Yu } \\
\text { Long County, Lijiang City }\end{array}$ & 18 & $\begin{array}{l}\text { Pine and oak mixed } \\
\text { forest, mountain } \\
\text { slope }\end{array}$ & $26^{\circ} 50^{\prime} 12.29^{\prime}$ & $100^{\circ} 10^{\prime} 51.28^{\prime \prime}$ & 2557 \\
\hline \multirow[t]{8}{*}{ MD } & YP & $\begin{array}{l}\text { Yingpan Township, Lanping } \\
\text { County, Nujiang Lisu } \\
\text { Autonomous Prefecture }\end{array}$ & 14 & $\begin{array}{l}\text { Pine and oak mixed } \\
\text { forest, mountain } \\
\text { slope }\end{array}$ & $26^{\circ} 24^{\prime} 02.33^{\prime \prime}$ & $99^{\circ} 06^{\prime} 43.62^{\prime \prime}$ & 2290 \\
\hline & $\mathrm{LJ}$ & $\begin{array}{l}\text { Lajing Township, Lanping } \\
\text { County, Nujiang Lisu } \\
\text { Autonomous Prefecture }\end{array}$ & 14 & $\begin{array}{l}\text { Pine and oak mixed } \\
\text { forest, mountain } \\
\text { slope }\end{array}$ & $26^{\circ} 30^{\prime} 11.69^{\prime \prime}$ & $99^{\circ} 15^{\prime} 13.60^{\prime \prime}$ & 2220 \\
\hline & $\mathrm{LZ}$ & $\begin{array}{l}\text { Luzhang Township, Lushui } \\
\text { County, Nujiang Lisu } \\
\text { Autonomous Prefecture }\end{array}$ & 17 & Oak forest, valley & $25^{\circ} 56^{\prime} 48.28^{\prime \prime}$ & $98^{\circ} 46^{\prime} 18.81^{\prime \prime}$ & 2142 \\
\hline & $\mathrm{CX}$ & $\begin{array}{l}\text { Changxin Township, } \\
\text { Yunlong County, Dali Bai } \\
\text { Autonomous Prefecture }\end{array}$ & 14 & $\begin{array}{l}\text { Pine and oak mixed } \\
\text { forest, mountain } \\
\text { slope }\end{array}$ & $26^{\circ} 03^{\prime} 50.08^{\prime \prime}$ & $99^{\circ} 26^{\prime} 30.24^{\prime \prime}$ & 1949 \\
\hline & $\mathrm{BC}$ & $\begin{array}{l}\text { Biaocun Township, Yunlong } \\
\text { County, Dali Bai } \\
\text { Autonomous Prefecture }\end{array}$ & 11 & Oak forest, escarpment & $26^{\circ} 64^{\prime} 43.36^{\prime \prime}$ & $99^{\circ} 07^{\prime} 38.72^{\prime \prime}$ & 1385 \\
\hline & $\mathrm{JZ}$ & $\begin{array}{l}\text { Jiuzhou Township, Yunlong } \\
\text { County, Dali Bai } \\
\text { Autonomous Prefecture }\end{array}$ & 11 & Oak forest, valley & $25^{\circ} 45^{\prime} 02.33^{\prime \prime}$ & $99^{\circ} 13^{\prime} 40.58^{\prime \prime}$ & 1380 \\
\hline & $\mathrm{JC}$ & $\begin{array}{l}\text { Jiancao Township, Yunlong } \\
\text { County, Dali Bai } \\
\text { Autonomous Prefecture }\end{array}$ & 16 & Oak forest, vale & $26^{\circ} 09^{\prime} 03.65^{\prime \prime}$ & $99^{\circ} 17^{\prime} 27.17^{\prime \prime}$ & 2160 \\
\hline & $\mathrm{BF}$ & $\begin{array}{l}\text { Baofeng Township, Yunlong } \\
\text { County, Dali Bai } \\
\text { Autonomous Prefecture }\end{array}$ & 14 & $\begin{array}{l}\text { Oak forest, mountain } \\
\text { slope }\end{array}$ & $25^{\circ} 48^{\prime} 28.97^{\prime \prime}$ & $99^{\circ} 22^{\prime} 15.96^{\prime \prime}$ & 1638 \\
\hline
\end{tabular}


Table 1. (Continued)

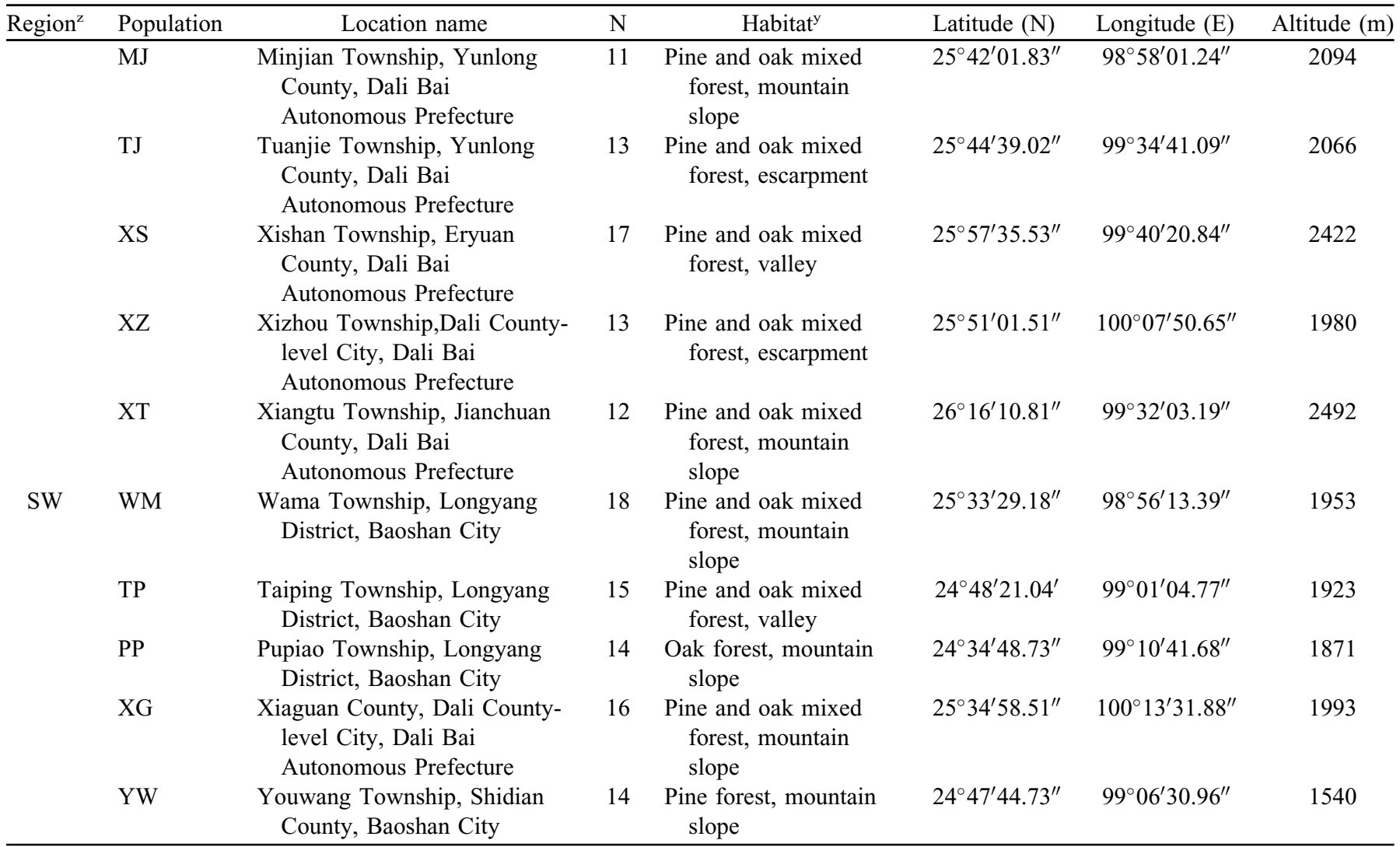

${ }^{\mathrm{z}} \mathrm{NW}=$ northern region of three parallel rivers in the western Yunnan Province; MD $=$ middle region of three parallel rivers in the western Yunnan Province; SW = Southern region of three parallel rivers in the western Yunnan Province.

${ }^{\text {y } P i n e ~(P i n u s ~ y u n n a n e n s i s), ~ o a k ~(Q u e r c u s ~ a q u i f o l i o i d e s), ~ a n d ~ b a m b o o ~(F a r g e s i a ~ p l e n i c u l m i s) . ~}$

limited to morphological diversity (Suo et al., 2016; Ye et al., 2015), nuclear simple sequence repeats [nSSR (Zhao et al., 2017)] and direct amplification of length polymorphism [DALP (Jia et al., 2012)]. Moreover, population samples in other studies represented less than $10 \%$ of the wild C. tortisepalum found in Yunnan Province and were lower than the sample size in this study. Furthermore, there is no report about the genetic diversity and structure of wild $C$. tortisepalum base on chloroplast DNA (cpDNA). Therefore, it is highly important to further explore the genetic diversity of populations and the genetic structure of wild C. tortisepalum based on cpDNA in Yunnan Province to adopt appropriate references for the formation of effective conservation strategies.

The chloroplast genome, as an independent genetic unit not subjected to genetic recombination and whose selection pressure is small, can directly reflect the genetic variation accumulated with a plant species during long-term evolution (Jiang et al., 2019; Ning et al., 2020; Schaal et al., 1998). It is highly suitable for investigating the genetic relationships and genetic diversity of the species in a geographic location (Liu et al., 2012) and has been widely used (Petit et al., 2005; Shaw et al., 2007; Sun et al., 2019; Yang et al., 2013).

In our study, 404 wild individuals from 28 populations in Yunnan Province were used as experimental materials, and their genetic structure and their lineage differentiation were investigated by cpDNA sequence analysis. The purpose of our study is to provide a theoretical basis for the formation of a protection strategy and to provide technical support for the industrial development of wild C. tortisepalum in Yunnan Province of China.

\section{Methods}

EXPERIMENTAL MATERIAL. On the basis of two investigations of the wild C. tortisepalum resources in Yunnan Province before sampling, 28 sampling sites located in the western area of the Yunnan Province were determined. Approximately 15 to 24 individuals were selected from each population with a distance of at least $20 \mathrm{~m}$. Finally, 404 individuals from 28 populations of wild C. tortisepalum were collected between 2010 and 2011. Afterward, $1 \mathrm{~g}$ of leaves were sampled from each plant, sealed in a bag, and placed in a sealing box with desiccant. Prepared materials were stored at $-80^{\circ} \mathrm{C}$ in the Southwest China Germplasm Bank of Wild Species (Kunming, China). The collection area name, latitude, longitude, altitude, and habitat were recorded for each sample. Detailed locations and geographic distribution of the populations are shown in Table 1 and Fig. 1.

Total DNA extraction. Genomic DNA was extracted from a single individual using the cetyltrimethylammonium bromide (CTAB) method (Doyle, 1986) with some modifications (Tang, 2014). The quality and quantity of the DNA were checked on $1 \%$ agarose gels. The extracted DNA was diluted to $50 \mathrm{ng} \cdot \mu \mathrm{L}^{-1}$ and stored at $-20^{\circ} \mathrm{C}$ for future use.

Polymerase Chain Reaction AMPlification AND SEQuenCing. On the basis of complete chloroplast genome sequence of the 


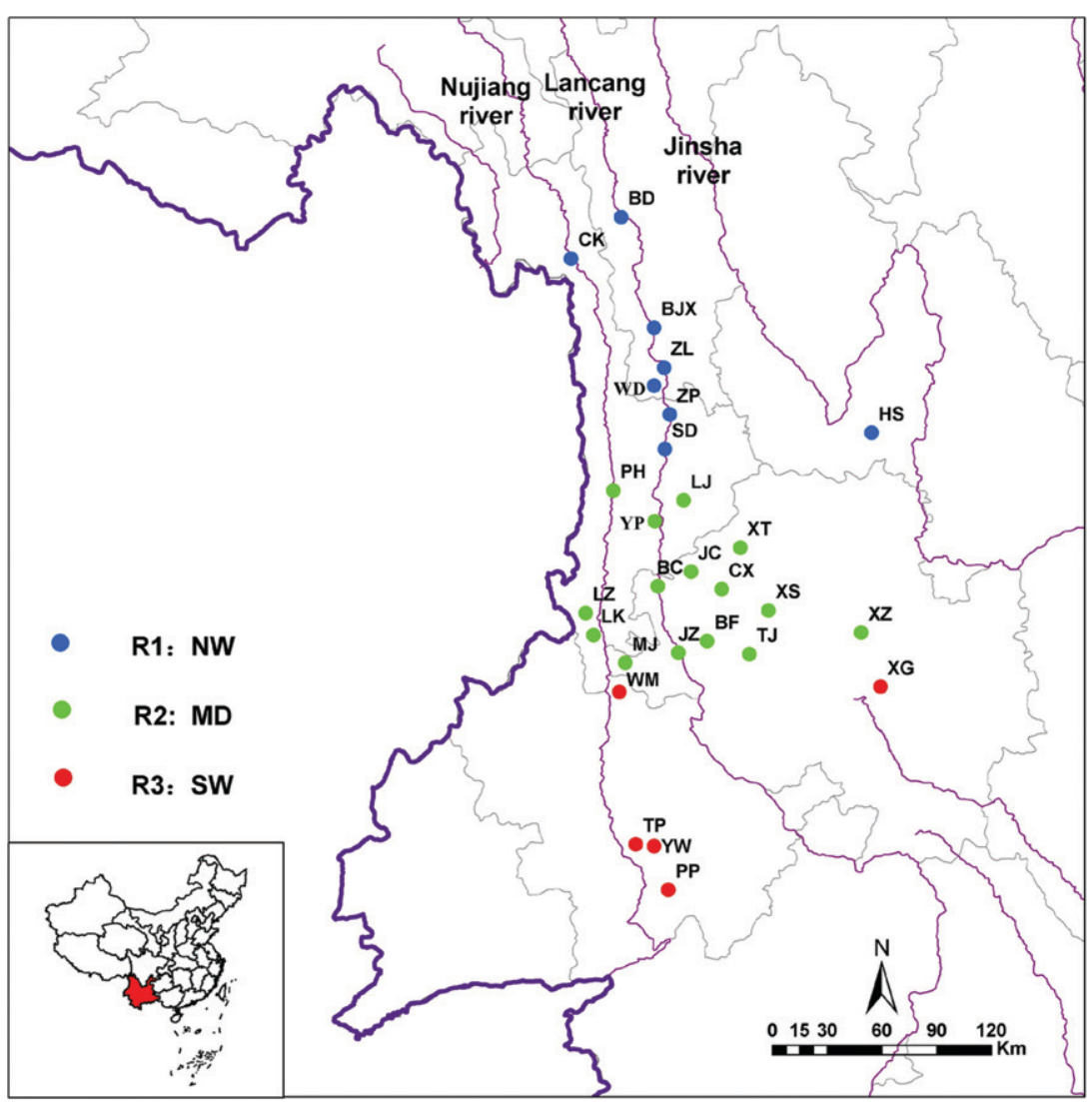

Fig. 1. Simplified map showing the geographic distribution of the 28 sampling sites of Cymbidium tortisepalum in Yunnan Province, China. Blue marks represent populations in the northern region of three parallel rivers in the western Yunnan Province (NW); green marks markers represent those in the middle region of three parallel rivers in the western Yunnan Province (MD), and red marks represent those in the southern region of three parallel rivers in the western Yunnan Province. The abbreviations of the sites refer to Table 1 .

$(5 \mu \mathrm{M}), 1.0 \mu \mathrm{L}$ primer R $(5 \mu \mathrm{M})$ DNA, 0.125 $\mu \mathrm{L}$ Taq polymerase $\left(5 \mathrm{U} \cdot \mu \mathrm{L}^{-1}\right), 2 \mu \mathrm{L}$ Template DNA (50 ng. $\mu \mathrm{L}^{-1}$ ), and then adding double-distilled water $\left(\mathrm{ddH}_{2} \mathrm{O}\right)$ to a total volume of $25 \mu \mathrm{L}$. The cycling parameters were as follows: 3 min of denaturation at $94^{\circ} \mathrm{C}$; followed by 35 cycles of 1 min denaturation at $94^{\circ} \mathrm{C}, 1.5 \mathrm{~min}$ annealing at $56^{\circ} \mathrm{C}$, and $2 \mathrm{~min}$ extension at $72^{\circ} \mathrm{C}$; with a final extension of $72^{\circ} \mathrm{C}$ for 10 min. PCR products were visualized using gel electrophoresis on an agarose gel $(0.8 \%$ to $1 \%)$. Sequencing of PCR products was accomplished using a DNA analyzer (ABI 3730; Thermo Fisher Scientific, Waltham, MA).

Data ANALYSIS. Sequencher version 4.1.4 software (Larkin et al., 2014) was used for sequence splicing. Geneious version 4.8 (Drummond et al., 2011) was used for sequence alignment and calibration. DnaSP version 5.0 software (Librado and Rozas, 2009) was used to perform haplotype statistics and sites with gaps were not considered in our analysis. ArcMap software (version 9.3; ESRI, Redlands, CA) was adopted to construct the geographic information map of all haplotypes within each population (Gmbh, 2004). Network version 4.6 software (Forster et al., 2007) was used to construct a haplotype network diagram. Arlequin version 3.5 (Excoffier and Lischer, 2010) was used to detect the genetic structure and perform analysis of molecular variance (AMOVA). GenALEx version 6.5 (Peakall and Smouse, 2006) was used to calculate the geographic distance, and the Mantel test (Mantel, 1967) was used to test the correlation between the two matrices.

genus C. tortisepalum by our research group (Yang et al., 2013), we selected 43 regions for designing polymerase chain reaction (PCR) primers. Of these, six chloroplast fragments had variable sites (psbM-trnD, trnV-trnA, accD-psal, rrn23, trnk-rps16, and ycfl) among 10 tested samples in the pilot study, which were finally used to sequence all samples. Sequences were deposited at GenBank with accession numbers KY621375-KY621467.

PCR amplification was performed using a thermal cycler (GeneAmp PCR System 9700; PerkinElmer, Waltham, MA). Primer information is shown in Table 2. PCR reactions were 25 $\mu \mathrm{L}$ in volume and contained $2.5 \mu \mathrm{L} 10 \times$ PCR buffer, $2.5 \mu \mathrm{L}$ $\mathrm{MgCl}_{2}$ (25 mM), $2.0 \mu \mathrm{L}$ dNTP mixture (2.5 mM), $1.0 \mu \mathrm{L}$ primer $\mathrm{F}$
Genetic diversity $\left(H_{S}\right)$, the total genetic diversity $\left(H_{T}\right)$, and the genetic differentiation coefficients $\left(G_{S T}\right.$ and $\left.N_{S T}\right)$ were calculated using Permut version 2.0 software (Pons and Petit, 1996), $G_{S T}$ and $N_{S T}$ were compared via the $U$ statistical method (1000 repeated permutation test) (Nei, 1987; Tajima, 1993). We used MEGA5 (Tamura et al., 2011) to construct a phylogenetic tree with neighbor-joining (NJ) method. Arlequin version 3.5 (Excoffier and Lischer, 2010) was used to perform mismatch analyze and calculate the Tajima's D (Tajima, 1993, 1996) and Fu's parameters (Fu, 1997) based on the infinite alleles model. DnaSP version 5.0 (Librado et al., 2009) was employed to construct mismatch distribution diagram. Our results suggested that although

Table 2. Primer sequences for the six genetic loci of wild Cymbidium tortisepalum in Yunnan Province, China. In our previous study (Yang et al., 2013), 43 primer sequences were designed based on complete chloroplast genome sequence and six chloroplast fragments had variable sites among 10 tested samples in the pilot study, which were finally used to sequence all samples. The sequence has been deposited at GenBank with accession numbers KY621375-KY621467.

\begin{tabular}{lll}
\hline Region & Forward sequence $\left(5^{\prime}-3^{\prime}\right)$ & Reverse sequence $\left(5^{\prime}-3^{\prime}\right)$ \\
\hline trnk-rps16 & TCCACCGATGAGTTAGCA & ATGTTGAGGAAGGCAGAAT \\
psbM-trnD & GTCATCTAAACCCGAAAAGT & ATTTGAAGAGCGACCATACT \\
trnV-trnA & TGGGCTCTTTCATCAACT & CAGGGTCTCCATCACTTC \\
accD-psal & ACGATGAAGATAAGGATGGGAGA & TGCGATTGCTGGAAAGACTA \\
rrn23 & ACGGTAAACGCTGGGTAG & AGTTCGGGATGGATTGGT \\
ycf1 & TATTTCGGTATTCTTTAGGTA & ACTTATCTTCCCTGTCCC \\
\hline
\end{tabular}


Table 3. Distribution frequencies of the 11 haplotypes in the 28 populations of wild Cymbidium tortisepalum in Yunnan Province, China.

\begin{tabular}{|c|c|c|c|c|c|}
\hline Population & Location & No. & Haplotype distribution & $H d$ & $\pi^{\mathrm{z}}\left(\times 10^{-2}\right)$ \\
\hline $\mathrm{BD}$ & Badi Township, Weixi County, Diqing Tibetan Autonomous Prefecture & 15 & $\mathrm{H} 1(7), \mathrm{H} 3(8)$ & 0.600 & 0.051 \\
\hline $\mathrm{BJX}$ & Baijixun Township, Weixi County, Diqing Tibetan Autonomous Prefecture & 17 & $\mathrm{H} 1(15), \mathrm{H} 3(2)$ & 0.221 & 0.028 \\
\hline WD & Weideng Township, Weixi County, Diqing Tibetan Autonomous Prefecture & 17 & H1(11), H3(6) & 0.522 & 0.046 \\
\hline $\mathrm{CK}$ & Cikai Township, Gongshan County, Nujiang Lisu Autonomous Prefecture & 15 & $\mathrm{H} 1(13), \mathrm{H} 2(1), \mathrm{H} 3(1)$ & 0.371 & 0.067 \\
\hline SD & Shideng Township, Lanping County, Nujiang Lisu Autonomous Prefecture & 13 & $\mathrm{H} 1(12), \mathrm{H} 5(1)$ & 0.154 & 0.006 \\
\hline $\mathrm{ZP}$ & Zhongpai Township, Lanping County, Nujiang Lisu Autonomous Prefecture & 14 & $\mathrm{H} 1(12), \mathrm{H} 3(1), \mathrm{H} 4(1)$ & 0.396 & 0.059 \\
\hline YP & Yingpan Township, Lanping County, Nujiang Lisu Autonomous Prefecture & 14 & $\mathrm{H} 1(10), \mathrm{H} 2(1), \mathrm{H} 3(3)$ & 0.505 & 0.089 \\
\hline $\mathrm{LJ}$ & Lajing Township, Lanping County, Nujiang Lisu Autonomous Prefecture & 14 & H1(14) & 0.000 & 0.000 \\
\hline PH & Pihe Township, Fugong County, Nujiang Lisu Autonomous Prefecture & 11 & $\mathrm{H} 1(8), \mathrm{H} 4(1), \mathrm{H} 8(2)$ & 0.473 & 0.044 \\
\hline LK & Liuku Township, Lushui County, Nujiang Lisu Autonomous Prefecture & 12 & $\mathrm{H} 1(11), \mathrm{H} 5(1)$ & 0.318 & 0.013 \\
\hline $\mathrm{LZ}$ & Luzhang Township, Lushui County, Nujiang Lisu Autonomous Prefecture & 17 & $\mathrm{H} 1(13), \mathrm{H} 4(2), \mathrm{H} 6(1), \mathrm{H} 7(1)$ & 0.507 & 0.083 \\
\hline $\mathrm{CX}$ & Changxin Township, Yunlong County, Dali Bai Autonomous Prefecture & 14 & H1(10), H2(2), H3(1), H5(1) & 0.495 & 0.119 \\
\hline MJ & Minjian Township, Yunlong County, Dali Bai Autonomous Prefecture & 11 & $\mathrm{H} 1(10), \mathrm{H} 3(1)$ & 0.345 & 0.031 \\
\hline $\mathrm{TJ}$ & Tuanjie Township, Yunlong County, Dali Bai Autonomous Prefecture & 13 & H1(13) & 0.282 & 0.012 \\
\hline XS & Xishan Township, Eryuan County, Dali Bai Autonomous Prefecture & 17 & H1(15), H3(1), H5(1) & 0.331 & 0.030 \\
\hline $\mathrm{XZ}$ & Xizhou Township,Dali County-level City, Dali Bai Autonomous Prefecture & 13 & $\mathrm{H} 1(11), \mathrm{H} 2(2)$ & 0.295 & 0.197 \\
\hline $\mathrm{XT}$ & Xiangtu Township, Jianchuan County, Dali Bai Autonomous Prefecture & 12 & $\mathrm{H} 1(12)$ & 0.000 & 0.000 \\
\hline WM & Wama Township, Longyang District, Baoshan City & 18 & $\mathrm{H} 1(18)$ & 0.000 & 0.000 \\
\hline $\mathrm{TP}$ & Taiping Township, Longyang District, Baoshan City & 15 & H1(13), H2(1), H11(1) & 0.371 & 0.107 \\
\hline $\mathrm{PP}$ & Pupiao Township, Longyang District, Baoshan City & 14 & H1(10), H9(3), H10(1) & 0.495 & 0.339 \\
\hline $\mathrm{XG}$ & Xiaguan County, Dali County-level City, Dali Bai Autonomous Prefecture & 16 & $\mathrm{H} 1(16)$ & 0.000 & 0.000 \\
\hline YW & Youwang Township, Shidian County, Baoshan City & 14 & H1(14) & 0.000 & 0.000 \\
\hline Mean & & & & 0.269 & 0.055 \\
\hline
\end{tabular}

${ }^{\mathrm{z}} H d=$ haplotype diversity; $\pi=$ nucleotide diversity.

these methods and indices were commonly to infer population expansion, they vary in sensitivity and in their adaptability to data.

\section{Results}

SEQUENCE CHARACTERISTICS AND HAPLOTYPE DISTRIBUTION. A sequence with a total length of $2702 \mathrm{bp}$ was obtained from the six chloroplast fragments of the 404 individuals of wild C. tortisepalum from the Yunnan Province. Sixty-one mutation sites were detected, which included 50 indels and 11 haplotypes based on 11 base substitution sites. The distribution of each haplotype with the population is shown in Table 3 and Fig. 2.

Among the six sequences, the sequence length of the chloroplast trnk-rps16 fragment was the longest, which was $786 \mathrm{bp}$, and two base substitutions were detected. The sequence length of the chloroplast trnV-trnA fragment was the second longest at $704 \mathrm{bp}$, with two base substitutions. The sequence length of the chloroplast fragments psbM-trnD, accD-psal, rrn23, and ycfl, were $171,283,486$, and $272 \mathrm{bp}$, respectively. There were only three, one, two, and one polymorphic loci detected in these fragments, respectively.

Nine of the 28 wild populations of $C$. tortisepalum sampled contained only one haplotype ( $32 \%$ of the population is within a single haplotype group). The remaining 19 populations showed polymorphisms, which included two to four haplotypes. Haplotypes H6, H7, H10, and H11 existed within only one individual, which were private haplotypes belonging to some of the populations. $\mathrm{H} 6$ and $\mathrm{H} 7$, two kinds of private haplotypes, both were distributed in the Luzhang (LZ) population. The haplotypes H10 and H11 were only found in the Pupiao (PP) population. Among the 11 haplotypes, $\mathrm{H} 1$ was the most widely distributed, and was present in all 28 populations. The H3 haplotype was the second most widely distributed.

GENETIC DIVERSITY AND GENETIC STRUCTURE. Results revealed that the genetic diversity of wild $C$. tortisepalum at the species level $\left(H_{T}=0.204, \pi=0.00024\right)$ and population level were low. In regard to genetic differentiation, there was no significant differentiation among populations $\left(G_{S T}=0.099, N_{S T}=0.081\right)$. The higher $G_{S T}$ value than $N_{S T}$ value, indicates that the probability of the presence of haplotypes with close relation in the same or similar populations is low and there is no significant phylogeographic structure within the wild $C$. tortisepalum populations (Tables 4 and 5).

AMOVA revealed that the greatest genetic variance $(\approx 91 \%)$ came from individuals within the population of wild $C$. tortisepalum, and the remaining $9.001 \%$ of the genetic variation existed among the populations, which indicated there is no clear genetic differentiation among populations (Table 6).

The results of the Mantel test analysis showed that the genetic distance of the wild $C$. tortisepalum had no significant correlation with geographical distance $(r=0.279, P=$ 0.020 ). The NJ adjacency tree constructed by the nonforeign group is shown in Fig. 3. Results revealed that 11 haplotypes 


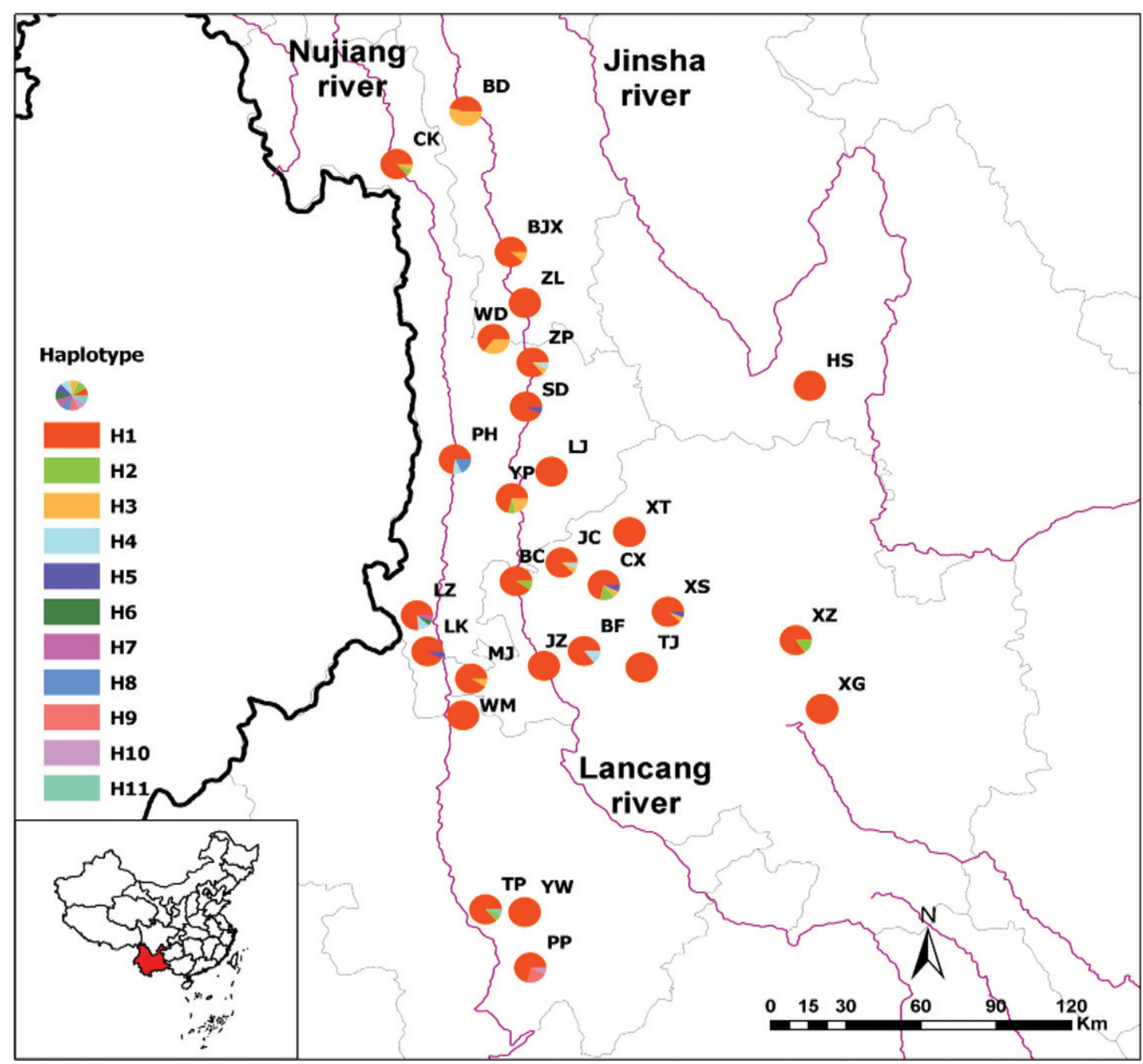

Fig. 2. Geographic distribution of the chloroplast DNA haplotypes of wild Cymbidium tortisepalum in Yunnan Province, China. Different colors in the label box represent different haplotypes, and the pie charts represent the distribution proportion of each haplotype in the populations.

of the wild C. tortisepalum formed six major branches with a $75 \%$ bootstrap value and six haplotypes (H2, H3, H6, H9, $\mathrm{H} 10$, and H11) constituted an independent branch. In addition, the remaining five haplotypes formed the collateral independent branch. The chloroplast haplotype network diagram constructed using the network of wild C. tortisepalum is shown in Fig. 4. All the haplotypes constituted a relatively simple linear relationship.

Mismatch analysis and neutral TEST. We examined the expansion history of wild $C$. tortisepalum using the tools of mismatch analysis and neutral test (Table 5, Fig. 5). According to the results of mismatch analysis, the

Table 4. Total genetic diversity of wild Cymbidium tortisepalum based on chloroplast DNA in Yunnan Province, China. Average genetic diversity within populations $\left(H_{S}\right)$, the total genetic diversity $\left(H_{T}\right)$, the genetic differentiation coefficients $\left(G_{S T}\right)$ and number of substitution $\left(N_{S T}\right)$ were calculated using Permut version 2.0 software (Pons and Petit, 1996), $G_{S T}$ and $N_{S T}$ were compared via the U statistical method [1000 repeated permutation test (Nei, 1987; Tajima, 1993)].

\begin{tabular}{|c|c|c|c|c|c|}
\hline Region $^{z}$ & $H s$ & $H_{T}$ & $G_{S T}$ & $N_{S T}$ & $P$ \\
\hline \multicolumn{6}{|c|}{ Mean (SE) } \\
\hline Total & $0.216(0.0334)$ & $0.240(0.0402)$ & $0.099(0.0391)$ & $0.081(0.0233)$ & $0.0000^{* *}$ \\
\hline NW & $0.241(0.0695)$ & $0.299(0.0886)$ & $0.196(\mathrm{NC})$ & $0.153(0.0533)$ & $0.0006 * *$ \\
\hline MD & $0.227(0.4652)$ & $0.234(0.0459)$ & $0.029(\mathrm{NC})$ & $0.026(\mathrm{NC})$ & $0.0362 *$ \\
\hline SW & $0.150(0.0994)$ & $0.164(0.1016)$ & $0.082(\mathrm{NC})$ & $0.148(\mathrm{NC})$ & 0.1273 \\
\hline
\end{tabular}

${ }^{\mathrm{z}} \mathrm{NW}=$ northern region of three parallel rivers in the western Yunnan Province; $\mathrm{MD}=$ middle region of three parallel rivers in the western Yunnan Province; SW = southern region of three parallel rivers in the western Yunnan Province.

*,**Significant at $P<0.05$ or 0.01 , respectively; data with no asterisks indicate that no significant difference found. 
Table 5. Genetic diversity and neutral test of wild Cymbidium tortisepalum based on chloroplast DNA in Yunnan Province, China.

\begin{tabular}{lccccccc}
\hline Groups $^{\mathrm{z}}$ & $\mathrm{Ns}^{\mathrm{y}}$ & $\pi$ & $H_{d}$ & $\mathrm{SSD}$ & HRag & $\mathrm{D}$ & $\mathrm{F}^{*}$ \\
\hline Total & 404 & 0.00024 & 0.241 & 0.06159 & 0.27860 & -0.51328 & 0.19961 \\
$\mathrm{NW}$ & 127 & 0.00018 & 0.285 & 0.05533 & 0.25750 & -0.29468 & 0.27766 \\
$\mathrm{MD}$ & 200 & 0.00031 & 0.241 & 0.02168 & 0.16689 & -0.86229 & 0.33932 \\
$\mathrm{SW}$ & 77 & 0.00044 & 0.150 & 0.07484 & 0.17983 & -0.07948 & 0.85512 \\
\hline \\
z $\mathrm{NW}=$ northern region of three parallel rivers in the western Yun- \\
nan Province; MD = middle region of three parallel rivers in the \\
western Yunnan Province; SW = southern region of three parallel \\
rivers in the western Yunnan Province. \\
y Ns = number of sequences; $\pi=$ nucleotide diversity; $H_{d}=$ haplo- \\
type diversity; SSD = sum of squared deviation under expansion \\
model; HRag = Harpending's raggedness index; D = Tajima's D \\
statistic; F = Fu and Li's F* test statistic.
\end{tabular}

Harpending's raggedness (HRag) index of C. tortisepalum changed as a curve with a single peak both in the overall level or the three division areas and the observed values were in good agreement with the expected values, which indicated that the populations might have experienced rapid expansion, or it may have been caused by high mobility among neighboring groups accompanied with rapid population expansion. However, this inference was not supported by the neutral test because no significant differences were found among Tajima's $D$ value and Fu and Li's value.

\section{Discussion}

Population GenetiC Diversity AND GENETIC DifFERENTIATION. Chloroplast DNA is characterized by the small genome, maternal inheritance of angiosperm, and small selection pressure and rapid variation of its nonencoding area (Wolfe et al., 1989). Therefore, it is highly suitable for studies on natural population genetic structure, the system evolution of plants. This study reports the largest survey of molecular diversity of native C. tortisepalumto date, with 404 individiuals from 28 populations sequenced at six cpDNA fragments. The total genetic diversity of wild C. tortisepalum was low. The reason for this result may be firstly related to the properties of the chloroplast genome. The chloroplast genome is a haploidisation of the cytoplasmic genome, and its evolutionary rate is low. Compared with the nuclear genome, the effective population size reflected by the chloroplast genome is much smaller, which is about half of the nuclear genes (Birky, 1988). In addition, long-term human activities that exert pressure on the population cause a sharp reduction in the number of groups in the distribution of the population. According to our investigations in recent years, the distribution of wild C. tortisepalum in Dali, Nujiang, Baoshan, and other places has been in declining state due to overutilization of the species. The effective population has been severely reduced and the random genetic drift intensified, which has caused the loss of genetic diversity (Tang, 2014). Furthermore, as the effective size of the populations decrease, the effects of random genetic drift and the bottleneck effect on chloroplast genome are more severe than those on the nuclear genome. The loss of genetic diversity, reflected by the chloroplast genome, is also amplified (Jordano and Godoy, 2000; Xun et al., 2011).

Alternatively, the results of this study may be related to the narrow geographic distribution and breeding system of this species. Wild resources of $C$. tortisepalum are mainly concentrated in the Dali Bai Autonomous Region, the Nujiang Lisu Nationality Autonomous Prefecture, Baoshan City, Lijiang City, and the Diqing Tibetan Autonomous Prefecture in the Yunnan Province. In general, species with a small distribution tend to have lower genetic diversity than those with a wide range distribution.

AMOVA of the cpDNA sequence results showed that the genetic differentiation of wild $C$. tortisepalum primarily existed within the populations (91\%), and genetic differentiation among populations $\left(F_{S C}=8.4 \%\right)$ and divergence among all populations $\left(F_{S T}=0.09001\right)$ were relatively low, which was consistent with the theory that $90 \%$ of variation exists within populations of cross-pollinated plants (Hamrickn and Godt,1990). A similar result of $89.25 \%$ molecular variation within populations was obtained in our previous investigation involving AMOVA of SSR data of these plants (Tang, 2014; Zhao et al., 2017), which, combined with the present results, indicate that the genetic background of wild $C$. tortisepalum is relatively simple, and there are no complex lineage differentiations. Low genetic differentiation of wild C. tortisepalum may be due to its unique life history, its highly specialized floral traits, its long evolutionary history, and severe bottlenecks, which the species may have experienced during the last ice age, as well as the fragmentation of the population distribution region with effects on seed and pollen flow.

The nucleotide polymorphism $(H d=0.241)$ and haplotype polymorphism $\left(\pi=0.24 \times 10^{2}\right)$ of $C$. tortisepalum at the species level were low. The genetic diversity of this species was primarily concentrated within populations $\left(H_{S}=0.216\right)$, which was consistent with the results of a study by Jia et al., (2012). At the species level, the $N_{S T}$ value was less than the $G_{S T}$ value $(P>0.05)$, which indicated that the probability of closely related haplotypes in the same or similar populations was low and that- there was no clear spectrum structure of the 28 populations in this study. This result was consistent with that of our previous study on SSR (Tang, 2014), which was in agreement with the theory that there is no significant correlation between geographic distance and genetic distance among outcrossing species, especially species with a small geographic distribution (Willyard et al., 2007).

Table 6. Analyses of molecular variance of wild Cymbidium tortisepalum based on chloroplast DNA in Yunnan Province, China.

\begin{tabular}{llcccc}
\hline Loci & Source of variation & df & Sum of squares & Variance component & Fixation indices \\
\hline Six & Among groups & 2 & 1.311 & $0.00130 \mathrm{Va}$ & $0.01874 \mathrm{Vb}$ \\
Loci & Among populations & 25 & 11.793 & $F_{C T}=0.00598$ \\
& Within groups & & & $0.20289 \mathrm{Vc}$ & $F_{S C}=0.08454$ \\
& Within populations & 376 & 76.287 & 0.22293 & $F_{S T}=0.09001$
\end{tabular}

${ }^{\mathrm{z}} F_{C T}=$ genetic diversity between regions; $F_{S C}=$ differentiation among individuals among populations; $F_{S T}=$ divergence among all populations. 


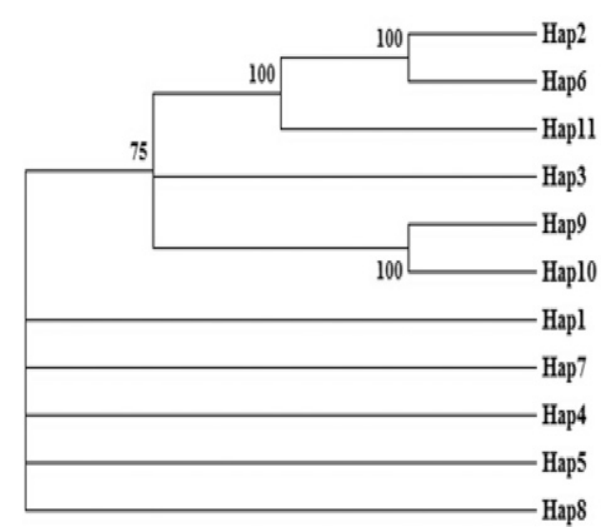

Fig. 3. Neighbor-joining trees obtained by analysis of 11 chloroplast DNA haplotypes of wild Cymbidium tortisepalum in Yunnan Province, China. Hap1-Hap11 represent 11 haplotypes, respectively. Bootstrap values $(>50 \%)$ are based on 1000 replicates and are indicated above branches.

The level of genetic diversity within a species depends on the breeding system, especially the number of effective populations and their variation among generations, which has significance to the future evolution and survival of the species. Endemic, rare, or endangered species are generally considered to have low levels of genetic diversity, due to low population numbers, the isolation of populations, and their adaptation to a single habitat (Barrett and Kohn, 1991). The genetic diversity of the endangered and their nonendangered species were compared by Frankham (1995) and Spielman et al. (2004), which demonstrated that the genetic diversity of most endangered species was lower than that of corresponding nonendangered species. However, results

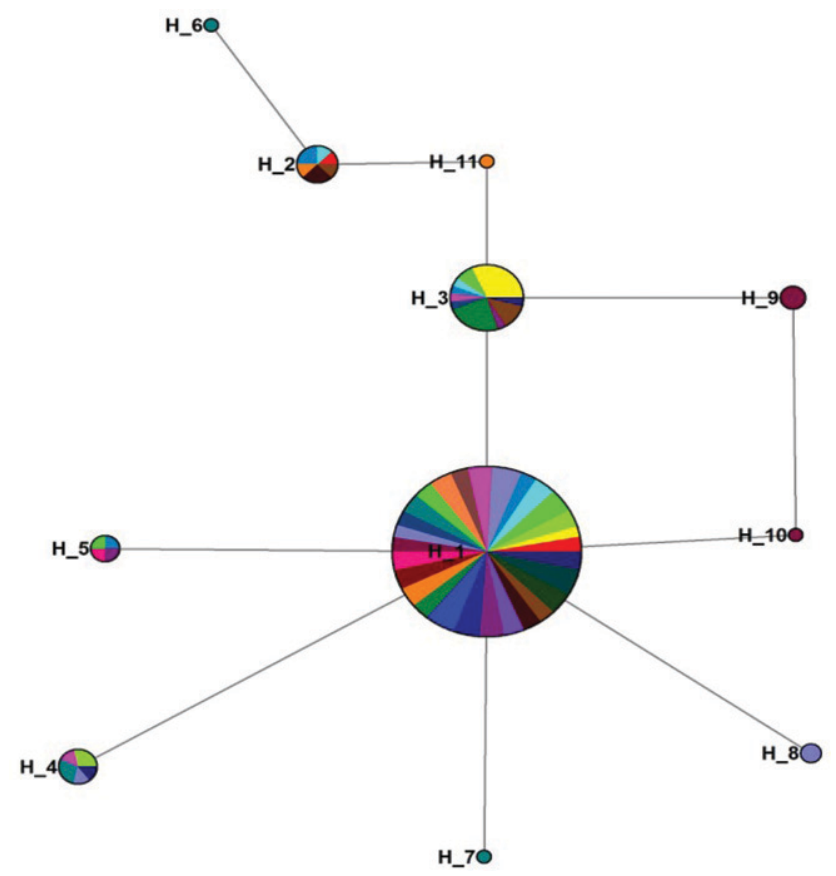

Fig. 4. The haplotype network of 11 chloroplast DNA haplotypes detected in 28 populations of wild Cymbidium tortisepalum in Yunnan Province, China. The size of circles corresponds to the frequency of each haplotype, H1-H11, represent 11 haplotypes, respectively, with each solid line representing one step mutation. of another study revealed that the genetic diversity level was still high for some endangered species, such as Iris aphylla (Wroblewska et al., 2003), Suzukia luchuensis (Maki et al., 2003), and Sarracenia leucophylla (Wang et al., 2004).

Chloroplast haplotype analysis. When interpreting the haplotype network diagram, the newly derived haplotype is often located at the tip of the clade, while the ancestral haplotypes are usually found in interior node (Crandall and Templeton, 1993; Schaal et al., 1998; Templeton, 1998). The most widely distributed haplotype, H1, located in the central position, was the ancestral haplotype, and $\mathrm{H} 5, \mathrm{H} 8, \mathrm{H} 4$, and the unique haplotypes $\mathrm{H} 6$ and $\mathrm{H} 7$, located at the end of the network, were the newly derived haplotypes.

Moreover, the haplotype diversity of the Bady (BD) population located in Badi Township in Diqing Weixi County was the highest. The number of haplotypes (four) was the highest in the Changxin (CX) population located in Dali and the LZ population located in the NuJiang region. The private haplotypes H10 and H11 found in PP and Taiping (TP) populations located in Pupiao and Taiping town of Baoshan Longyang District, respectively. Populations in a refuge should have a higher genetic diversity than those in a nonrefuge, and they should contain the ancestral (or ancient) haplotype (Hewitt, 1999, 2004; Lascoux et al., 2004; Petit et al., 2005). It can be inferred that BD, CX, Lushui (LS), and the towns of PP and TP in Baoshan may have been a refuge for wild $C$. tortisepalum during the last ice age, and these areas may have richer resources of wild $C$. tortisepalum.

CONSERVATION AND FUTURE STUDIES ON WILD $C$. TORTISEPALUM. Orchidaceae is one of the largest families of flowering plants, although most are rare and endangered plants. All wild orchid species are included in Appendix II of the Convention on International Trade in Endangered Species of Wild Fauna and Flora. The main goal for protecting an endangered species is to conserve its genetic diversity because the species may only survive and adapt to the environmental changes by maintaining sufficient genetic variation within and among populations (Barrett and Kohn, 1991). The results of this study showed that the total genetic diversity and genetic deviation of wild $C$. tortisepalum, as analyzed by cpDNA, were low. Therefore, this species may have a relatively low tolerance to ecologic or random climatic events and natural phenomena. On the basis of our investigation, we considered that the main cause in impending danger to wild $C$. tortisepalum resources was not due to its genetic basis and biological characteristics but to habitat fragmentation and the rapid decrease in the number of populations and the number of individuals within populations, which is caused by habitat destruction and overutilization by humans. We found that the survey region for wild C. tortisepalum had experienced severe habitat destruction, which made it difficult to find wild $C$. tortisepalum resources in its reported distribution areas. Most of the populations were small, and the individuals in the population were scattered. With time, the loss of genetic diversity would further exacerbate the endangered status of this species. Therefore, to maintain the long-term survival of this species, the protection of the habitat of wild C. tortisepalum is critical. As possible refuges for resources of wild C. tortisepalum, BD, CX, LS, $\mathrm{PP}$, and TP towns should be given priority for protection and future studies.

The results of this study also showed that the vast majority of genetic variation in wild $C$. tortisepalum was located within populations. The haplotype frequency had a large difference within populations, and low frequency haplotypes accounted for the 
A

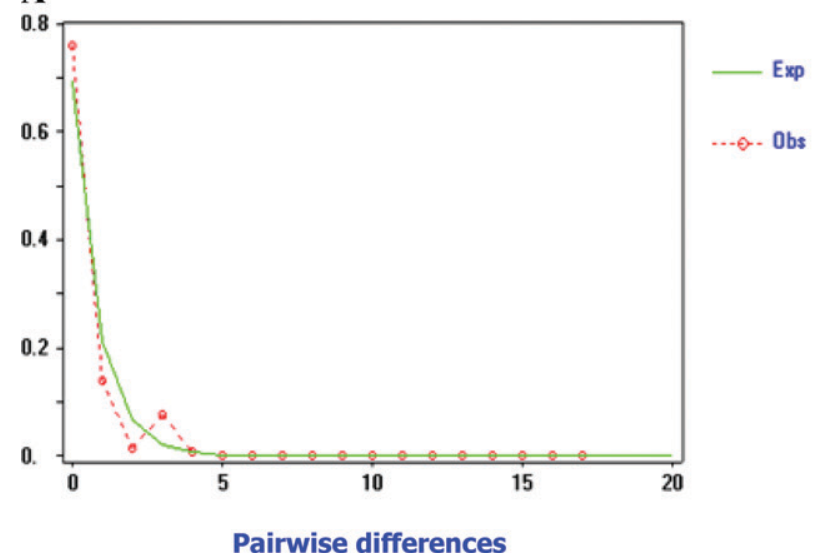

C

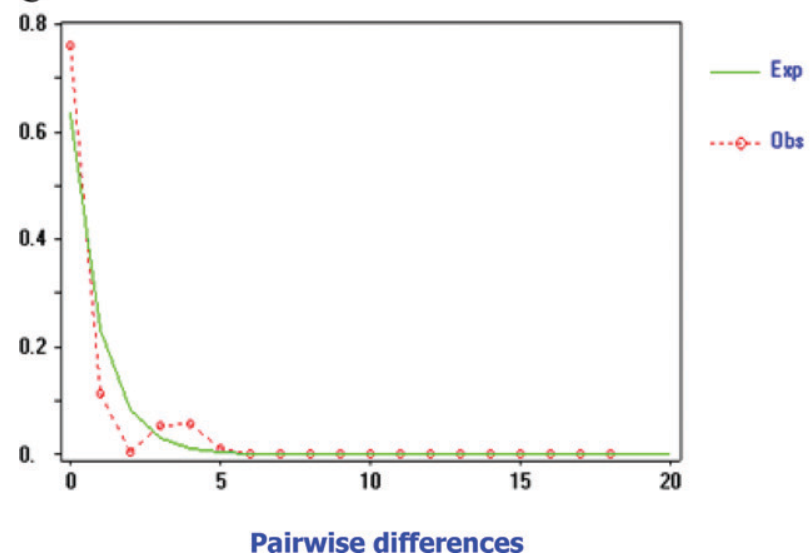

B

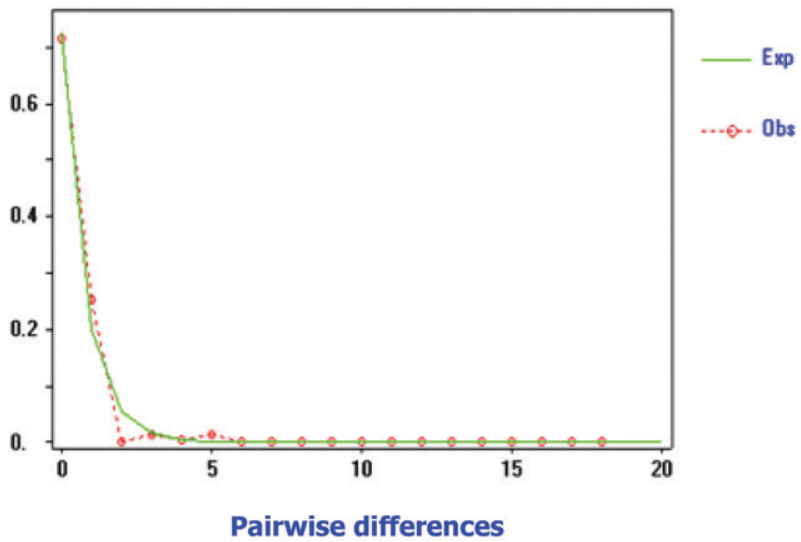

D

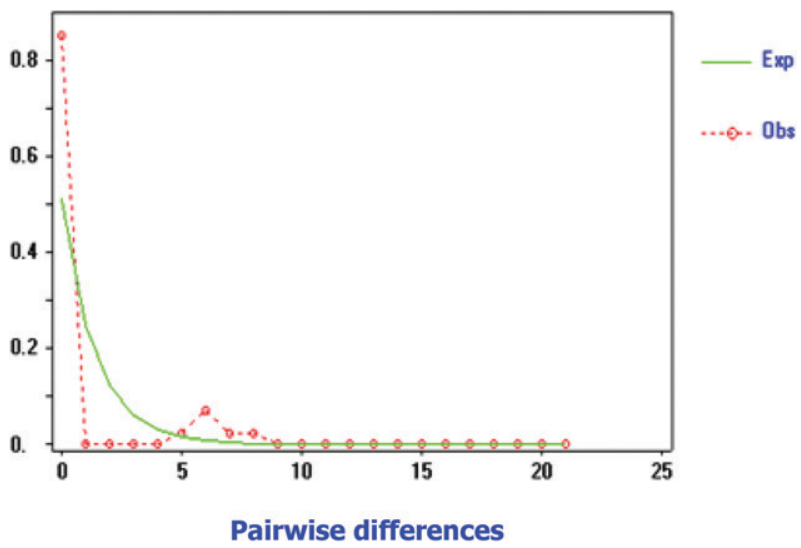

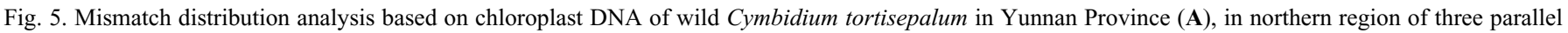
rivers in the western Yunnan Province (B), in middle region of three parallel rivers in the western Yunnan Province (C), and in southern region of three parallel rivers in the western Yunnan Province (D). Solid lines indicate expected value (Exp), dotted lines reflect observed value (Obs).

majority of the populations. The low frequency of haplotypes was likely caused by decreases in the populations and random genetic drift and also the result of declining genetic diversity within populations. Therefore, we suggest that the number of populations could be reduced and that individuals from each population should be increased for conservation or sampling. In particular, this protection strategy should be preferred in populations with high genetic diversity and low frequency haplotype groups.

Future studies should be based on the investigation of largescale resources, with the collection of as many representative population samples as possible from areas with less human activity and more simple ecological climates, such as the Diqing Tibetan Autonomous Region. The diversity and genetic differentiation of wild $C$. tortisepalum should be studied by the method of single-copy nuclear gene sequence and cpDNA sequences of a certain length, which would provide a more reliable basis for further elucidation of the genetic diversity and the population genetic differentiation patterns of wild C. tortisepalum.

\section{Literature Cited}

Barrett, S.C.H. and J.R. Kohn. 1991. Genetic and evolutionary consequences of small population size in plants: implications for conservation, p. 1-30. In: Genetics and conservation of rare plants. Oxford University Press, New York, NY.
Birky, C.W. 1988. Evolution and variation in plant chloroplast and mitochondrial genomes, p. 23-54. In: L.D. Gottlieb and S.K. Jain (eds.). Plant evolutionary biology. Chapman and Hall, London, UK.

Crandall, K.A. and A.R. Templeton. 1993. Empirical tests of some predictions from coalescent theory with application to intraspecific phylogeny reconstruction. Genetics 134(3):959-969, https://doi.org/ 10.1101/gad.7.7b.1459.

Doyle, J. 1986. Genomic plant DNA preparation from fresh tissue-CTAB method. Ecol. Evol. 1(1):9-10, https://doi.org/10.1111/mec.12131.

Drummond, A.J., B. Ashton, M. Cheung, J. Heled, and M. Kearse. 2011. Geneious v4.8 Auckland. Biomatters, Wellington, New Zealand.

Du Puy, D. and P. Cribb. 1988. The genus Cymbidium. Timber Press, Portland, OR.

Excoffier, L. and H.E.L. Lischer. 2010. Arlequin suite ver 3.5: A new series of programs to perform population genetics analyses under Linux and Windows. Mol. Ecol. Resour. 10(3):564-567, https://doi. org/10.1111/j.1755-0998.2010.02847.x.

Forster, M., P. Forster, and J. Watson. 2007. Network version 4.4.0.1: A software for population genetics data analysis. Fluxus Technology, Clare, UK.

Frankham, R. 1995. Conservation genetics. Annu. Rev. Genet. 29:305-327.

Fu, Y.X. 1997. Statistical tests of neutrality of mutations against population growth, hitchhiking and background selection. Genetics 147(2):915-925, https://doi.org/10.1017/S0016672397002966.

Gmbh, E.G. 2004. ArcGI server administrator and developer guide. ESRI, Redlands, CA. 
Hamrick, J.L. and M. Godt. 1990. Allozyme diversity in plants species. Sinauer Assoc., Sunderland, MA.

He, S.X., R.G. Xue, W.W. Tang, C.L. Xu, and C.G. Guo. 2019. Efficient cultivation tecniques of Cymbidium tortisepalum. Agr. Eng. Techol. 7:19-22, https://doi.org/10.16815/j.cnki.11-5436/s.2019.19.003.

Hewitt, G.M. 1999. Post-glacial re-colonization of European biota. Biol. J. Linn. Soc. Lond. 68(1-2):87-112, https://doi.org/10.1006/ bij1.1999.0332.

Hewitt, G.M. 2004. Genetic consequence of climate oscillations in the Quaternary. Philos. Trans. R. Soc. Lond. Ser. B Biol. Sci. 359(1442): 183-195, https://doi.org/10.1098/rstb.2003.1388.

Huan, L.V.T. and M. Tanake. 2004. Effects of red and blue light-emitting diodes on callus induction, callus proliferation, and protocormlike body formation from callus in Cymbidium orchid. Environ. Control Biol. 42(1):57-64, https://doi.org/10.2525/ecb1963.42.57.

Jia, L., Y.D. Shi, H. Yu, Y. Luo, and Y.Y. Li. 2012. Genetic diversity of Cymbidium tortisepalum by DALP. Guihaia 32(6):822-827, https://doi.org/10.3969/j.issn.1000-3142.2012.06.020.

Jiang, Y.T., R.Q. Lin, B. Liu, Q.M. Zeng, Z.J. Liu, and S.P. Chen. 2019. Complete chloroplast genome of Cymbidium ensifolium (Orchidaceae). Mitochondrial DNA B Resour. 4(2):2236-2237, https://doi.org/10.1080/23802359.2019.1624637.

Jordano, P. and J.A. Godoy. 2000. RAPD variation and population genetic structure in Prunus mahaleb (Rosaceae), an animal-dispersed tree. Mol. Ecol. 9(9):1293-1305, https://doi.org/10.1046/ j.1365-294x.2000.01009.x.

Larkin, M.A., G. Blackshields, N.P. Brown, R. Chenna, P.A. Mcgettigan, and H. Mcwilliam. 2014. Clustal W and Clustal X version 2.0. Bioinformatics 23(21):2947-2948, https://doi.org/10.1093/bioinformatics/ btm404.

Lascoux, M., A.E. Palme, R. Cheddadi, and R.G. Latta. 2004. Impact of ice ages on the genetic structure of tree and shrubs. Philos. Trans. R. Soc. Lond. Ser. B-Biol. Sci. 359(1442):197-207, https://doi.org/ 10.1098/rstb.2003.1390.

Li, H.F., Z.L. Zhao, H.Z. Zhang, M. Li, and G.M. Liu. 2010. Hybridization and hybrid seed germination in situ of endangered Cymbidium tortisepalum. Acta. Bot. Boreal-Occident. Sin. 30: 541-545, doi: CNKI: SUN:DNYX.0.2010-03-020.

Li, H.F., Z.L. Zhao, and G.M. Liu. 2009. Study on effects of different transplantation medium on test-tube plantlet of Cymbidium torliseplum. J. Anhui Agr. Sci. 37: 9950-9951, https://doi.org/CNKI: SUN:AHNY.0.2009-21-055.

Librado, P. and J. Rozas. 2009. DnaSP v5: A software for comprehensive analysis of DNA polymorphism data. Bioinformatics 25(11):1451-1452, https://doi.org/10.1093/bioinformatics/btp187.

Lin, T.P., H.Y. Liu, C.F. Hsieh, and K.H. Wang. 2016. Complete list of the native orchids of Taiwan and their type information. Taiwania 61:78-126, https://doi.org/10.6165/tai.2016.61.78.

Liu, Y., S.X. Yang, P.Z. Ji, and L.Z. Gao. 2012. Phylogeography of Camellia taliensis (Theaceae) inferred from chloroplast and nuclear DNA: Insights into evolutionary history and conservation. BMC Evol. Biol. 12:92, https://doi.org/10.1186/1471-2148-12-92.

Maki, M., T. Yamashiro, and S. Matsumura. 2003. High levels of genetic diversity in island populations of the island endemic Suzukia luchuensis (Labiatae). Heredity 91:300-306, https://doi.org/10.1038/ sj.hdy.6800311.

Mantel, N. 1967. The detection of disease clustering and a generalized regression approach [J]. Cancer Res. 27(2):209-220.

Nei, M. 1987. Molecular evolutionary genetics. Columbia Univ. Press, New York, NY.

Ning, H.J., L. Shao, and S.L. Dai. 2020. The complete chloroplast genome of Cymbidium longibracteatum (Orchidaceae) and phylogenetic analysis. Mitochondrial DNA B Resour. 5(3):2948-2949, https://doi.org/10.1080/23802359.2020.1780968.

Peakall, R. and P.E. Smouse. 2006. Genelex6: Genetic analysis in Excel. Population genetic software for teaching and research. Mol. Ecol. Notes 6:288-295, https://doi.org/10.1111/j.1471-8286.2005.01155.x.
Peng, C.R. 2003. Orchid boutique. Fujian Sci. Technol. Press, Fuzhou, China.

Petit, R.J., J. Duminil, S. Fineschi, A. Hampe, D. Salvini, and G.G. Vendramin. 2005. Comparative organization of chloroplast, mitochondrial and nuclear diversity in plant populations. Mol. Ecol. 14(3):689-701, https://doi.org/10.1111/j.1365-294X.2004.02410.x.

Pons, O. and R.J. Petit. 1996. Measuring and testing genetic differentiation with ordered versus unordered alleles. Genetics 144(3):1237-1245, https://doi.org/10.1093/genetics/144.3.1237.

Qi, F.Y. 2004. Conservation and development strategy for Cymbidium lianpan resource of Weixi. Forest Invent. Plann. 29(2):105-108, https://doi.org/10.3969/j.issn.1671-3168.2004.02.027.

Rao Q., J.L. Wang, and S.R. Guo. 2008. A preliminary study on habitat change of wild lotus orchid. Chinese Wild Plant Res. 27(4):20-22, https://doi.org/CNKI:SUN:ZYSZ.0.2008-04-006.

Schaal, B.A., D.A. Hayworth, K.M. Olsen, J.T. Rauscher, and W.A. Smith. 1998. Phylogeographic studies in plants: Problems and prospects. Mol. Ecol. 7(4):465-474, https://doi.org/10.1046/j.1365-294x. 1998.00318.x.

Shaw, J., B.E. Lickey, E.E. Schilling, and R.L. Small. 2007. Comparison of whole chloroplast genome sequences to choose non-coding regions for phylogenetic studies in angiosperms: The tortoise and the hare III. Amer. J. Bot. 94(3):275-288, https://doi.org/10.3732/ajb. 94.3.275.

Spielman, D.B., W. Brook, and R. Frankham. 2004. Most species are not driven to extinction before genetic factors impact them. Proc. Natl. Acad. Sci. USA 101:15621-15624, https://doi.org/ 10.1073/pnas.0403809101.

Sun, Y., Y. Chen, H. Lin, and X. Ma. 2019. The complete chloroplast genome of a Cymbidium tortisepalum (Orchidaceae) male mutant. Mitochondrial DNA B Resour. 4(2):4087-4088, https://doi.org/ $0.1080 / 23802359.2019 .1691948$.

Suo, M., Y.F. Bi, H.Z. Wang, M. Tang, and G. Ye. 2016. Relationship between morphology and elevation in native Cymbidium tortisepalum in Yunnan Province, China. Acta Ecol. Sin. 36(19):6170-6177, https://doi.org/10.5846/stxb201507261561.

Tajima, F. 1993. Simple methods for testing the molecular evolutionary clock hypothesis. Genetics 135(2):599-607, https://doi.org/ 10.1101/gad.7.10.2048.

Tajima, F. 1996. The amount of DNA polymorphism maintained in a finite population when the neutral mutation rate varies among sites. Genetics 143(3):1475, https://doi.org/10.1007/BF00120227.

Tamura, K., D. Peterson, N. Peterson, G. Stecher, M. Nei, and S. Kumar. 2011. MEGA5: Molecular evolutionary genetics analysis using maximum likelihood, evolutionary distance, and maximum parsimony methods. Mol. Biol. Evol. 28(10):2731-2739, https://doi. org/10.1093/molbev/msr121.

Tang, M. 2014. Wild population genetic structure and cultivars molecular identification of Cymbidium tortisepalum in Yunnan Province. Ph.D. Diss., Yunnan Agr. Univ., Kumming, China.

Teixeira da Silva, A. Jaime, and M. Tanaka. 2006. Multiple regeneration pathways via thin cell layers in hybrid Cymbidium (Orchidaceae). J. Plant Growth Regul. 25(3):203-210, https://doi.org/10.1007/ s00344-005-0104-0.

Templeton, A.R. 1998. Nested clade analyses of phylogeographic data: Testing hypotheses about gene flow and population history. Mol. Ecol. 7(4):381-397, https://doi.org/10.1046/j.1365-294x.1998.00308.x.

Wang, Z.F., J.L. Hamrick, and M.J. Godt. 2004. High genetic diversity in Sarracenia leucophylla (Sarraceniaceae), a carnivorous wetland herb. J. Hered. 95:234-243, https://doi.org/10.1093/jhered/esh043.

Willyard, A., J. Syring, D.S. Gernandt, A. Liston, and R. Cronn. 2007. Fossil calibration of molecular divergence infers a moderate mutation rate and recent radiations for Pinus. Mol. Biol. Evol. 24(1):90-101, https://doi.org/10.1093/molbev/msl131.

Wolfe, K.H., W.H. Li, and P.M. Sharp. 1989. Rates of nucleotide substitution vary greatly among plant mitochondrial, chloroplast, and 
nuclear DNAs. Proc. Natl. Acad. Sci. USA 29:208-211, https://doi. org/10.1073/pnas.84.24.9054.

Wroblewska, A., E. Brzosko, B. Czarnecka, and J. Nowosielski. 2003. High levels of genetic diversity in populations of Iris aphylla L. (Iridaceae), an endangered species in Poland. Biol. J. Linn. Soc. Lond. 142:65-72, https://doi.org/10.1046/j.1095-8339.2003.00162.x.

Xue, R.G., S.X. He, Z.G. Li, J.W. He, S.H. Yang, and Y. Li. 2007. A review of conservation status of Cymbidium tortisepalum and the utilization. Forest Invent. Plann. 32(3):94-97, https://doi.org/10.3969/j. issn.1671-3168.2007.03.024.

Xun, G., S.S. Luan, K.H. Hung, C.C. Hwang, C.J. Lin, Y.C. Chiang, and T.Y. Chiang. 2011. Population structure of Nouelia insignis (Asteraceae), an endangered species in southwestern China, based on chloroplast DNA sequences: Recent demographic shrinking. J. Plant Res. 124(2):221-230, https:// doi.org/10.1007/s10265-010-0363-0.
Yang, J.B., M. Tang, H.T. Li, Z.R. Zhang, and D.Z. Li. 2013. Complete chloroplast genome of the genus Cymbidium: Lights into the species identification, phylogenetic implications and population genetic analyses. BMC Evol. Biol. 13:84, https://doi.org/10.1186/1471-2148-13-84.

Ye, G., M. Tang, H.Z. Wang, M. Suo, W.G. Che, X. Chen, and Y.F. Bi. 2015. Relationship between morphological differentiation and elevation of wild Cymbidium tortisepalum in Diqing of Yunnan Province. J. Yunnan Agr. Univ. 30(1):84-89, https://doi.org/10.16211/j.issn. 1004-390X(n).2015.01.014.

Zhao, Y., D. Li, and T. Liu. 2019. Pollination-Induced transcriptome and phylogenetic analysis in Cymbidium tortisepalum (Orchidaceae). Russ. J. Plant Physiol. 66:618-627, https://doi.org/10.1134/S1021443719040174.

Zhao, Y., M. Tang, and Y.F. Bi. 2017. Nuclear genetic diversity and population structure of a vulnerable and endemic orchid (Cymbidium tortisepalum) in Northwestern Yunnan, China. Scientia Hort. 219:22-30, https://doi.org/10.1016/j.scienta.2017.02.033. 